\title{
CORRECTION
}

\section{Correction to: Effectiveness of cleaning of workplace cytotoxic surface}

\author{
Laetitia Minh Mai Lê $\hat{e}^{1,2} \cdot$ Pierre Alain Jolivot ${ }^{3} \cdot$ Hassane Sadou Yayé ${ }^{4} \cdot$ André Rieutord $^{3} \cdot$ Agnès Bellanger $^{5}$. \\ Dominique Pradeau ${ }^{4}$. Séverine Barbault-Foucher ${ }^{3} \cdot$ Eric Caudron $^{1,2}$
}

Published online: 29 April 2021

(c) Springer-Verlag GmbH Germany, part of Springer Nature 2021

\section{Correction to: Int Arch Occup Environ Health (2013) 86:333-341 https://doi.org/10.1007/s00420-012-0769-1}

In the original publication of the article the third author's family name was incorrectly published, the correct name should read as Hassane Sadou Yayé.

This has been corrected in this paper.

Publisher's Note Springer Nature remains neutral with regard to jurisdictional claims in published maps and institutional affiliations.

The original article can be found online at https://doi.org/10.1007/ s00420-012-0769-1.

Eric Caudron

eric.caudron@u-psud.fr

1 University Paris-Sud, Châtenay-Malabry, France

2 European Georges Pompidou Hospital, Paris, France

3 Antoine Béclère Hospital, Clamart, France

4 Pharmaceutical Establishment of Paris Hospitals, Paris, France

5 Pitié-Salpêtrière Hospital, Paris, France 